\title{
UAR $00-4018$
}

\section{2}

\section{Explosive compaction of clad graphite powders and obtaining of coatings on their base}

\author{
Akaki B. Peikrishvili, ${ }^{*}$ Levan A. Japaridze, ${ }^{*}$ Karl P. Staudhammer, ${ }^{* *}$ Fernand S. Marquis, ${ }^{* * *}$ \\ Nikoloz M. Chikhradze,* Tamaz G. Gobejishvili,* Eka G. Bantzuri* \\ * The Academy of Science of Georgia, Institute of Mining Mechanics, Tbilisi , Georgia \\ ** Los Alamos National Laboratory, Los Alamos, USA \\ *** Department of Materials and Metallurgical Engineering, College of Materials Science Engineering, \\ South Dakota School of Mines and Technology, Rapid City, SD 57701,USA
}

In order to consolidate graphite based powders and in order to obtain coatings with density values near to the theoretical ones clad graphite powders of the $\mathrm{C}_{\text {graphite }}-\mathrm{Ni}\left(\mathrm{C}_{\mathrm{g}}-\mathrm{Ni}\right)$ compositions were explosively compacted under different loading conditions. Theoretical calculations revealed that for assessing the stressdeformed state of $C_{g}-\mathrm{Ni}$ compositions and computing the normal and tangent stress components (when $V_{D}<$ $C_{\text {longindinal }}$ and $V_{D}<C_{\text {transversal }}$ ) it is recommended to apply the dynamic problem's solution model while the pressure impulse $P=f(x)$ is being uniformly spread with constant rate along the boundary of a semi-infinite elastic body. The results of our experiments showed that it is possible to obtain high dense coatings from $C_{g}$ $\mathrm{Ni}$ compositions bonded by an intermediate layer to the substrate material. The structure and properties of the coatings depends on the intensity of the shock loading and temperature. The effect of the shock loading conditions (temperature, loading intensity) on the structure, properties and structure/properties relationships for the $\mathrm{C}_{\mathrm{g}}-\mathrm{Ni}$ coatings are discussed.

\section{INTRODUCTION}

A number of investigations [1-3] have been dedicated to the study of disturbance growth processes occurring in materials as a result of a rapid change caused by the explosive pressure. This process encompasses a multitude of complex phenomena. Based on the shock loading intensity level there exists the assumption that the solid body behaves either elastically or rather loses its rigidity and behaves as a liquid. Correspondingly to these assumptions every researcher faces the necessity of choosing one of two alternative theories: the elasticity theory and the hydrodynamic theory. The analysis given in general [4-7] shows that an increased number of authors are inclined to describe this phenomenon by the elasticity theory. Evidently this is linked with the necessity of a more precise theoretical description for the results of experiments on shock compression of solid materials (creation of new phases, formation of texture, directed contortion of the crystal lattice, etc.). The intensive shift deformations engender the problem linked with a value and proportion of the normal and tangent components of the stress. This problem concerns particularly the materials treatment by the sliding front edge of the detonation wave. The process due to its configuration, intensity and usability is efficient and attractive. This paper presents results of calculations of the stress conditions of nickel and of the system $\mathrm{C}_{\mathrm{g}}-\mathrm{Ni}$ under exposure to the shock loading, assuming that the load is being evenly spread with a constant rate at the ampoulesample boundary.

\section{MODELING OF SHOCK LOADING DEFORMATION STRESS}

It is of great importance from the scientific as well as the practical standpoint to define precisely the mode of deformation of materials while they are loaded with a shock pulse, the rate of which does not exceed the sound speed in the treated material. In this case calculations according to the hydrodynamic theory may lead to inaccuracies.

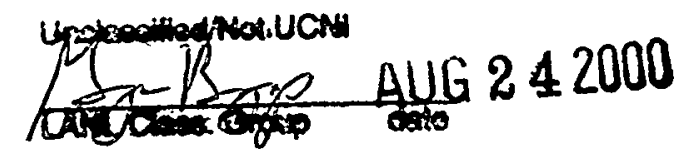




\section{DISCLAIMER}

This report was prepared as an account of work sponsored by an agency of the United States Government. Neither the United States Government nor any agency thereof, nor any of their employees, make any warranty, express or implied, or assumes any legal liability or responsibility for the accuracy, completeness, or usefulness of any information, apparatus, product, or process disclosed, or represents that its use would not infringe privately owned rights. Reference herein to any specific commercial product, process, or service by trade name, trademark, manufacturer, or otherwise does not necessarily constitute or imply its endorsement, recommendation, or favoring by the United States Government or any agency thereof. The views and opinions of authors expressed herein do not necessarily state or reflect those of the United States Government or any agency thereof. 


\section{DISCLAIMER}

Portions of this document may be illegible in electronic image products. Images are produced from the best available original document. 
Thus, the solution of this is to be found in the partial solutions of the dynamic problems.

Let us consider one of the versions of such a solution. The correlation between the components of stress and the displacement for solving dynamic problems when the equation of motion is:

$$
\begin{aligned}
& \frac{\partial \sigma_{x}}{\partial x}+\frac{\partial \tau_{x y}}{\partial y}=\rho \frac{\partial^{2} u}{\partial t^{2}} \\
& \frac{\partial \tau_{x y}}{\partial x}+\frac{\partial \sigma_{y}}{\partial y}=\rho \frac{\partial^{2} V}{\partial t^{2}}
\end{aligned}
$$

where $\rho$ is the material density, is the following:

$$
\sigma_{x}=\lambda\left(\frac{\partial u}{\partial x}+\frac{\partial V}{\partial y}\right)+2 \eta \frac{\partial u}{\partial x}
$$

$\sigma y=\lambda(\partial u / \partial x+\partial v / \partial y)+2 \mu \partial v / \partial y$

$\tau_{x y}=\mu(\partial v / \partial x+\partial u / \partial y)$ where $\lambda=E \sigma /(1+\sigma)(1-2 \sigma)$ and $\mu=E / 2(1+\sigma)$ are the Lame constant and the shear modulus.

By the introduction of secondary functions:

$\varphi(x, y, t)$ and $\psi(x, y, t)$, such as:

$\mathrm{U}=\partial \varphi / \partial \mathrm{x}+\partial \psi / \partial \mathrm{y} ; \quad \mathrm{V}=\hat{c} \varphi / \partial \mathrm{y}-\partial \psi / \partial \mathrm{x}$

and their appropriate transformation as well as the substitution of the provisional variable - $t$ with the space similar variable $-\tau$, the equation of motion (1) takes the form of:

$\partial^{2} \varphi / \partial \tau^{2}=\nabla_{1}^{2} \varphi ; \quad \beta \partial^{2} \psi / \partial \tau^{2}=\nabla_{1}^{2} \psi$

where:

$\beta^{2}=C_{1}{ }^{2} / C_{2}{ }^{2}=(\lambda+2 \mu) / \mu ; C_{1}{ }^{2}=(\lambda+2 \mu) / \rho ; \quad C_{2}{ }^{2}=\mu / \rho$

Solving the equation of motion (4) when to the boundary of semi-infinite body $y>0$ in the position $y=0$ is applied a discontinuous time-dependent pressure $\mathrm{P}=(\mathrm{x}, \tau)$ and using the Fourier inversion [8], for the pressure component, the general solution is obtained as integral expressions via the Fourier transform:

$$
\begin{gathered}
\sigma_{y}=-\frac{1}{2 \pi} \int_{-\infty}^{+\infty} \int_{-\infty}^{+\infty} \frac{\bar{p}}{f+g}\left[f e^{-\left(\xi^{2}-\beta^{2} \varsigma^{2}\right)^{1 / 2}}+g e^{-\left(\xi^{2}-\beta^{\left.\left.2 \xi^{2}\right)^{1} y\right)}\right] e^{-t(\bar{\xi}+\zeta \tau)} d \xi d \varsigma}\right. \\
\sigma_{x}+\sigma_{y}=-\frac{\lambda+\mu}{2 \eta \pi} \int_{-\infty}^{+\infty} \int_{-\infty}^{+\infty} \frac{\varsigma^{2} \bar{p}}{f+g}\left(\xi^{2}-\frac{1}{2} \beta^{2} \varsigma^{2}\right) e^{-\left(\xi^{2}-\varsigma^{2}\right)^{\frac{1}{2}} y-t(\xi x+\zeta \tau)} d \xi d \zeta \\
\tau_{x y}=\frac{1}{2 \pi} \int_{-\infty-\infty}^{+\infty+\infty} \frac{l \xi \bar{p}}{f+g}\left(\xi^{2}-\varsigma^{2}\right)\left(\xi^{2}-\frac{1}{2} \beta^{2} \varsigma^{2}\right)\left[e^{-\left(\xi^{2}-\varsigma^{2}\right)^{1 / 2 y}}-e^{-\left(\xi^{2}-\beta^{2} \varsigma^{2}\right)^{1 / 2 y}}\right] e^{-\imath(\xi x+\varsigma \tau)} d \xi d \tau
\end{gathered}
$$

where $P(\xi, \zeta)$ - is the two-dimensional transform of the Fourier function $P=(x, \tau)$,

$$
\bar{p}(\xi, \varsigma)=\frac{1}{2 \pi} \int_{-\infty-\infty}^{+\infty} \int_{-\infty}^{\infty} p(x, \tau) e^{\imath(\xi x+\xi \tau)} d x d \tau
$$

and the functions $f$ and $g$ are defined as:

$$
f\left(\xi^{2}, \varsigma^{2}\right)=-\left(\xi^{2}-\frac{1}{2} \beta^{2} \varsigma^{2}\right)^{2}
$$

$$
g\left(\xi^{2}, \varsigma^{2}\right)=\xi^{2}\left(\xi^{2}-\varsigma^{2}\right)^{\frac{1}{2}}\left(\xi^{2}-\beta^{2} \varsigma^{2}\right)^{\frac{1}{2}}
$$

Using the general solution presented in equation (5) for the determination of the stress inside the semi-infinite elastic body when the

\section{RECEIVED \\ DEC 132000


pressure impulse $\mathrm{P}=\chi(\mathrm{x})$ moves along the boundary y=0 with a constant rate $\vec{V}$ - and with

due regard for $P(x, \tau)=P(x-v t)$ the pressure components take the following form:

$$
\begin{aligned}
& \sigma_{y}=-\frac{2}{\pi} \int_{0}^{\infty} \chi(\xi) \cos \left[\xi(x-V t)\left[\frac{\theta}{\theta+\varphi} e^{-\left(1-\beta_{1}{ }^{2}\right) y \xi}+\frac{\varphi}{\theta+\varphi} e^{-\left(1-\beta_{2}{ }^{2}\right)^{1 / 2 v_{\xi}}}\right] d \xi\right. \\
& \sigma_{x}+\sigma_{y}=-\frac{2\left(1-\beta_{1}^{2}\right)^{1 / 2}\left(1-1 / 2 \beta_{2}^{2}\right)}{\pi \chi(\theta+\varphi)} \int_{0}^{\infty} \chi(\xi) e^{-\left(1-\beta_{1}^{2}\right)^{1 / 2} y \xi} \cos [\xi(x-V t)] d \xi \\
& \tau_{x y}=\frac{2\left(1-\beta_{1}{ }^{2}\right)\left(1-1 / 2 \beta_{2}^{2}\right)}{\pi(\theta+\varphi)} \int \chi(\xi)\left[e^{-\left(1-\beta_{1}{ }^{2}\right)^{1 / 2 y_{\xi}^{2}}}-e^{-\left(1-\beta_{2}{ }^{2}\right)^{1 / 2 y_{\xi}}}\right] \sin [\xi(x-V t)] d \xi
\end{aligned}
$$

If $\mathrm{P}$ is a point constant force applied to the boundary and $\chi(\xi)=0,5 \mathrm{P}$, then by the method of integral transformation we obtain from equation (8) for $\sigma_{y}$ the following expression:

$$
\begin{aligned}
\sigma_{y} & =-\frac{p}{\pi} \int_{0}^{\infty} \frac{\theta}{\theta+\varphi} e^{-\left(1-\beta_{1}{ }^{2}\right)^{1 / 2} y \xi} \cos [\xi(x-V t)] d \xi-\frac{p}{\pi} \int_{0}^{\infty} \frac{\varphi}{\theta+\varphi} e^{-\left(1-\beta_{2}{ }^{2}\right)^{1 / 2} y \xi} \cos [\xi(x-V t)] d \xi= \\
& =-\frac{p}{\pi}\left[\frac{\theta}{\theta+\varphi} \int_{0}^{\infty} e^{-\left(1-\beta_{1}{ }^{2}\right)^{1 / 2 y \xi}} \cos [\xi(x-V t)] d \xi+\frac{\varphi}{\theta+\varphi} \int_{0}^{\infty} e^{-\left(1-\beta_{2}{ }^{2}\right)^{1 / 2} y \xi} \cos [\xi(x-V t)] d \xi\right]
\end{aligned}
$$

It is evident that:

$$
\int_{0}^{\infty} e^{-b x} \cos a x d x=\frac{b}{a^{2}+b^{2}}
$$

$$
\int_{0}^{\infty} e^{-b x} \sin a x d x=\frac{a}{a^{2}+b^{2}}
$$

and

Where $a$ and $b$ are constant values. Then the equation (9) may be written in an explicit form:

$$
\sigma_{y}=-\frac{p y}{\pi}\left[\frac{\left(1-\beta_{1}^{2}\right)^{\frac{1}{2}}}{(x-V t)^{2}+\left(1-\beta_{1}^{2}\right) y^{2}} \cdot \frac{\theta}{\theta+\phi}+\frac{\left(1-\beta_{2}^{2}\right)^{\frac{1}{2}}}{(x-V t)^{2}+\left(1-\beta_{2}{ }^{2}\right) y^{2}} \cdot \frac{\varphi}{\theta+\varphi}\right]
$$

Similarly: 


$$
\begin{aligned}
& \sigma_{x}+\sigma_{y}=-\frac{p y}{\pi} \cdot \frac{\beta_{1}^{2}(\lambda+\mu)\left(1-\frac{1}{2} \beta_{2}^{2}\right)}{\mu(\theta+\varphi)} \cdot \frac{\left(1-\beta_{2}^{2}\right)^{\frac{1}{2}}}{(x-V t)^{2}+\left(1-\beta_{1}^{2}\right) y^{2}} \\
& \tau_{x y}=\frac{p}{\pi} \cdot \frac{\left(1-\beta_{1}^{2}\right)^{\frac{1}{2}}\left(1-\frac{1}{2} \beta_{2}^{2}\right)}{(\theta+\varphi)} \cdot\left[\frac{1}{(x-V t)^{2}+\left(1-\beta_{1}^{2}\right) y^{2}}-\frac{1}{(x-V t)^{2}+\left(1-\beta_{2}^{2}\right) y^{2}}\right] \cdot(x-V t)
\end{aligned}
$$

where $\theta=-\left(1-0,5 \beta_{2}^{2}\right)^{2} ; \quad \varphi=\left(1-\beta_{1}^{2}\right)^{1 / 2}\left(1-\beta_{2}{ }^{2}\right)^{12}$;

$\beta_{1}=V / C_{1} ; \beta_{2}=V / C_{2}$

As we can see from the equation (8) the stresses will be determined in multitude of real numbers if the conditions $1-\beta_{1}^{2}>0$ and $1-\beta_{2}^{2}>0$ are satisfied, where: $\beta_{1}=V / C_{1}<1 \Rightarrow V<C_{1}$ and $\beta_{2}=V / C_{2}<1 \Rightarrow V<C_{2}$.

Taking into consideration that the physical meaning of mathematical equations for $C_{1}$ and $C_{2}$ consists of their identity in accordance with longitudinal and diametrical sound speeds (as a rule $C_{1}>, C_{2}$ ) the following conclusion may be made: the chosen model describes with a sufficient precision the process of distribution and propagation of stress waves in solid materials when they are loaded by the pressure impulse - $P$ formed by the detonation wave's sliding front edge that is evenly spread along the boundary solid material-explosive substance with the rate $\mathrm{V}$, $\left(0<V<C_{1}\right)$ while this material is under the shock pulse.

In order to calculate the state of stress of the solid body when the pressure impulse rate exceeds the limits of the rates determined above, we need

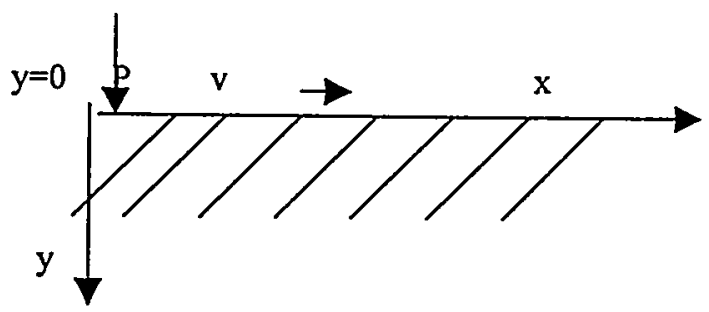

to consider the solid body as an incompressible liquid. In this case it is expedient to apply the hydrodynamic theory. This theory causes significant inaccuracies when the rates of active hydrodynamic pressures (shock waves rates) approach the upper limit to the sound speed (V $\rightarrow$ C).

\section{EXAMPLE}

Let us calculate the normal and tangent stresses in the solid $\mathrm{Ni}$ and in the clad powder $\mathrm{C}_{\mathrm{g}}-\mathrm{Ni}$ (when each graphite grain is coated by $\mathrm{Ni}$ ) during their treatment by the detonation wave's sliding front edge at normal and hot conditions, as shown in Figure 1. It is necessary to mention that the loaded composition is located inside the steel ampoule. The initiated pressure is being propagated along the treated surface at the boundary explosive material-ampoule with the constant rate $V=V_{\text {detonation. Therefore, for the }}$ calculation of the components of the stress tensor in the loaded material according to the method described above we can use (with a large approximation) the results of the solution from equation (8).

Figure 1. Loading of the material by the pressure pulse - $P$ evenly propagated along the boundary: $y=0$. 
In order to verify to what extent the experiments performed comply with the limits of the selected model of calculation we present below the characteristics of the explosive materials used and important constants for the nickel and graphite materials.

Table 1. Characteristics of the Explosive Materials Used in the Experiments [2, 9]

\begin{tabular}{|c|l|c|c|c|}
\hline $\mathrm{N}$ & \multicolumn{1}{|c|}{ Content } & $\begin{array}{c}\text { Density } \\
\rho \times 10^{3} \mathrm{KT} / \mathrm{m}^{3}\end{array}$ & $\begin{array}{c}\text { Detonation Velocity, } \\
\mathrm{m} / \mathrm{sec}\end{array}$ & $\begin{array}{c}\text { Pressure on Steel's Wall } \\
\mathrm{Px} 10^{9} \mathrm{~N} / \mathrm{m}^{2}\end{array}$ \\
\hline 1 & Ammonite 6ЖB & 1.25 & 3500 & 10 \\
\hline 2 & $\begin{array}{l}\text { Ammonite 6\%B+ } \\
50 \% \text { Saltpetre }\left(\mathrm{NH}_{4} \mathrm{NO}_{3}\right)\end{array}$ & 1.00 & 1700 & 5 \\
\hline
\end{tabular}

Table 2. Important Characteristics of Ni and Graphite [10]

\begin{tabular}{|c|c|c|c|c|c|c|}
\hline $\bar{N}$ & Material & $\begin{array}{l}\text { Density } \\
\rho \times 10^{3} \mathrm{kT} / \mathrm{m}^{3}\end{array}$ & $\begin{array}{l}\text { Young's } \\
\text { module } \\
\text { Ex } 10^{10} \mathrm{~N} / \mathrm{m}^{2}\end{array}$ & $\begin{array}{l}\text { Poisson } \\
\text { Ratio }\end{array}$ & $\begin{array}{l}\text { Shear module } \\
\mathrm{G} \times 10^{10} \mathrm{~N} / \mathrm{m}^{2}\end{array}$ & $\begin{array}{l}\text { Heat capacity } \\
\mathrm{Cal} / \mathrm{g}-\mathrm{K}\end{array}$ \\
\hline 1 & $\mathrm{Ni}-$ & 8.9 & 20.2 & 0.3 & 7.7 & 440 \\
\hline 2 & $\begin{array}{l}\mathrm{Ni} \text { - compacted at } \\
\text { static conditions } \\
\rho=60 \% \text { of } \\
\text { theoretical value }\end{array}$ & $5.16 f$ & $\cdots$ & 0.3 & 7.7 & 440 \\
\hline 3 & Graphite(monolite) & 2.25 & ---- & --- & $-\cdots$ & 710 \\
\hline 4 & $\begin{array}{l}\text { C-Ni } \\
(50 / 50) \text { vol \%. }\end{array}$ & 5.57 & $\overline{-----}$ & $-\cdots$ & -..-- & --- \\
\hline
\end{tabular}

Table 3. Variation of the Young's Module of Ni as a Function of the Temperature [11].

\begin{tabular}{|l|c|c|c|}
\hline T, K & 4 & 293 & 863 \\
\hline E, GPa & 239.1 & 202 & 187 \\
\hline
\end{tabular}

Since the loading effect on graphite particles of the clad $\mathrm{C}_{\mathrm{g}}-\mathrm{Ni}$ composition takes place trough the clad layer (Ni), we may consider the twodimensional system as a one-dimensional one and calculate the stresses for $\mathrm{Ni}$. During the determination of the parameters, and in accordance with the data presented in the tables 13 , it becomes evident that at a value of $\rho=8900 \mathrm{Kg} / \mathrm{m}^{3}$ and $V_{\text {detonation }}=3500 \mathrm{~m} / \mathrm{s}, \beta_{2}>1$ and for all other cases $\beta_{1}$ and $\beta_{2}$ meet all requirements of the models chosen. For the calculation of the stresses we have prepared the appropriate program and on the base of the data obtained we have constructed charts for relationships $\sigma_{y}=f\left(\mathrm{x}_{0}, \mathrm{y}, \mathrm{t}_{0}\right)$, as shown in Figures 2 and 3 . 

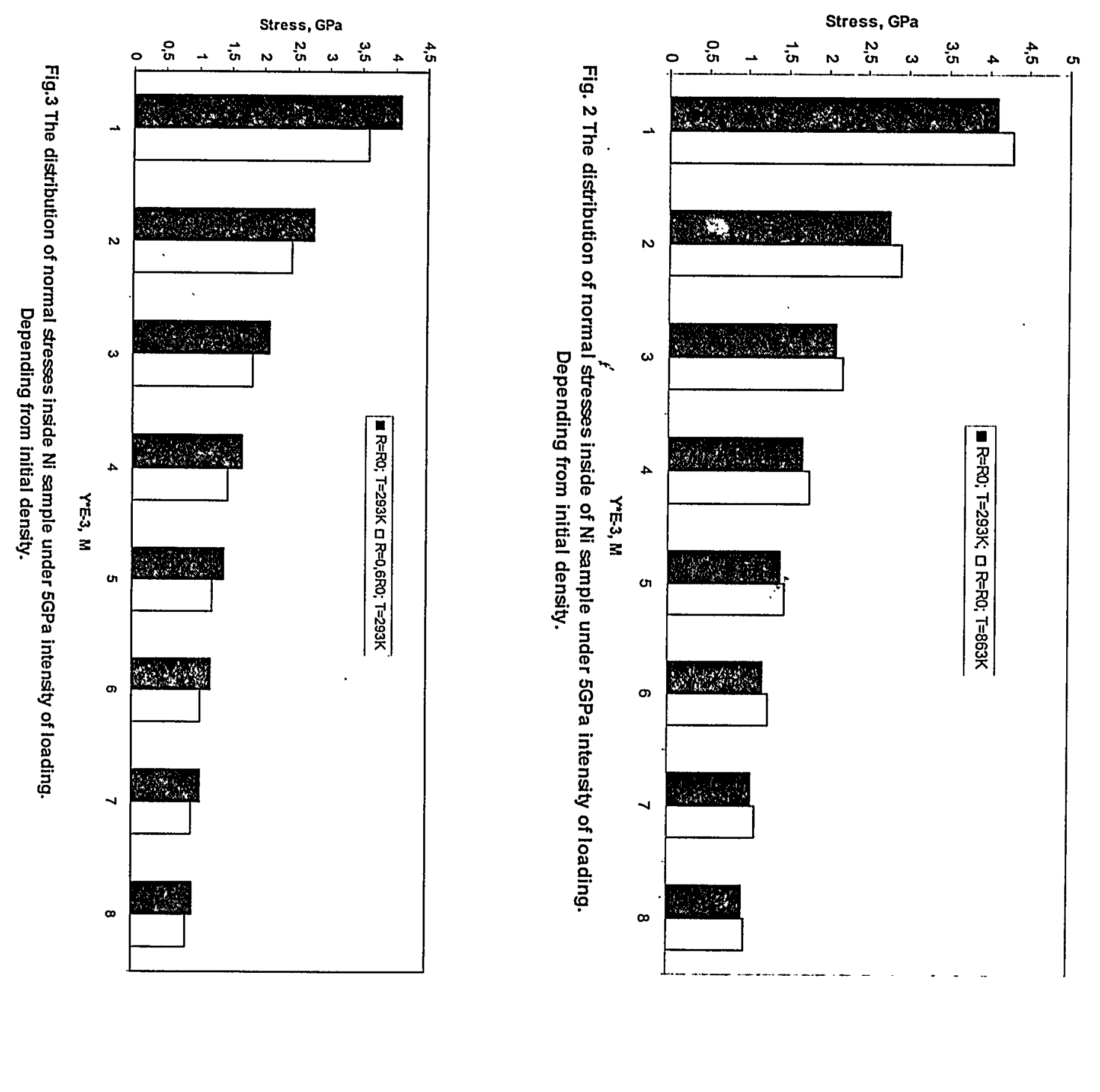


\section{KNOWLEDGE GENERATED BY THE MODELING}

The analysis of the results obtained permits us to establish the following conclusions:

1. With the raise of the initial temperature the pressure intensity of stress waves in the loaded sample is increased. For $\mathrm{Ni}$ as it is heated from $293 \mathrm{~K}$ to $863 \mathrm{~K}$ the average value of normal stress raises by approximately $10 \%$. Taking into account that for most solid materials the increase of temperature is accompanied by the reduction of the Young module, we may conclude that the phenomenon observed in $\mathrm{Ni}$ is also applicable to other solid materials. The resultant stress value can be split into two components: cold and thermal: $\sigma=\sigma_{\text {eol. }}+\sigma_{\text {ther. }}$. Thus in order to obtain high strength materials we recommend the use of low-rate industrial explosives and powder materials treated in hot conditions.

2. The value of the stress component is strongly sensitive to the initial density of the heat treated material. With the increase of porosity, the shock wave intensity is reduced. For Ni powders with a pre-density of up to $60 \%$ of the theoretical value, the reduction of normal stresses is approximately $11 \%$. This confirms the importance of the predensity and the gradual explosive treatment of powder materials.

3. The comparison of stress intensities in pure and clad graphite for similar heat treatment conditions $(\mathrm{P}=1.7 \mathrm{GPa})$ shows that in clad particles the stress is increased by $30 \%$. This establishes the beneficial role of cladding low-dense particles by high dense plastic (ductile) materials in the explosive compaction technology.

4. The results obtained allow the determination, for a specific composition the minimal thickness of the specimens when the stress developed in the whole bulk material surpasses the static and the dynamic yield strength of the material, and one of the key conditions of the deformation is maintained.

\section{FORMATION OF COATINGS FROM CLAD GRAPHITE - NI COMPOSITIONS}

In order to consolidate powders with the $\mathrm{C}_{\mathrm{g}}-\mathrm{Ni}$ composition with near theoretical density and in order to obtain coatings with the $\mathrm{C}_{\mathrm{g}}-\mathrm{Ni}$ composition, on the inner and outer surfaces of steel tubes the clad Graphite - Ni powders were obtained by the hydro-metallurgy method. The experiments were carried out using the experimental cylindrical set up for hot shock loading shown in Figure 4. The Graphite - Ni compound powder was placed between the steel container's wall (1) and the central steel rod (2) with a preliminary density of $60-70 \%$. The container was shut from both sides with plugs (4). Simultaneously, the plugs were used as heating contacts (4). Around the container is situated the cylindrical box (5) filled with the explosive materials (6). The assembly is heated up to the desired temperature using the method of resistance heating: When this temperature is reached, the initiation of the explosive materials is carried out, using the detonator and detonating cord (7). The consolidation and coating experiments were carried out in the temperature range of $293-1073$ K. An ammonite/saltpeter mixture with a detonation velocity of $3.2 \mathrm{~km} / \mathrm{sec}$ was used as the explosive material. After explosive loading and consolidation of the Graphite - Ni powders the steel central rod was removed by either mechanical and/or chemical processes. The steel tubes with the coated insert surfaces were then obtained. Figure 5 shows the macrostructure of the explosively consolidated $\mathrm{C}_{\mathrm{g}}-\mathrm{Ni}(50 / 50)$ coating layer situated between the central steel rod and tube. This coating is characterized by low density and high porosity. The investigation shows that the hardness distribution within the coating is not uniform and that it changes with the specific area of the compacts, as shown in Figure 6. With increasing intensity of loading and/or the application of preheating (loading of Graphite Ni powders in hot conditions) the density of the specimens obtained increases, and the values of hardness in different areas of the compact-coatings becomes uniform. The figure 6 represents the hardness distribution in Graphite - Ni compactcoatings obtained as a function of the of loading conditions. As shown, the value of the hardness depends on the intensity and temperature of the shock loading. With the increase of loading intensity the value of hardness of compact/coatings increases and they become stable. 

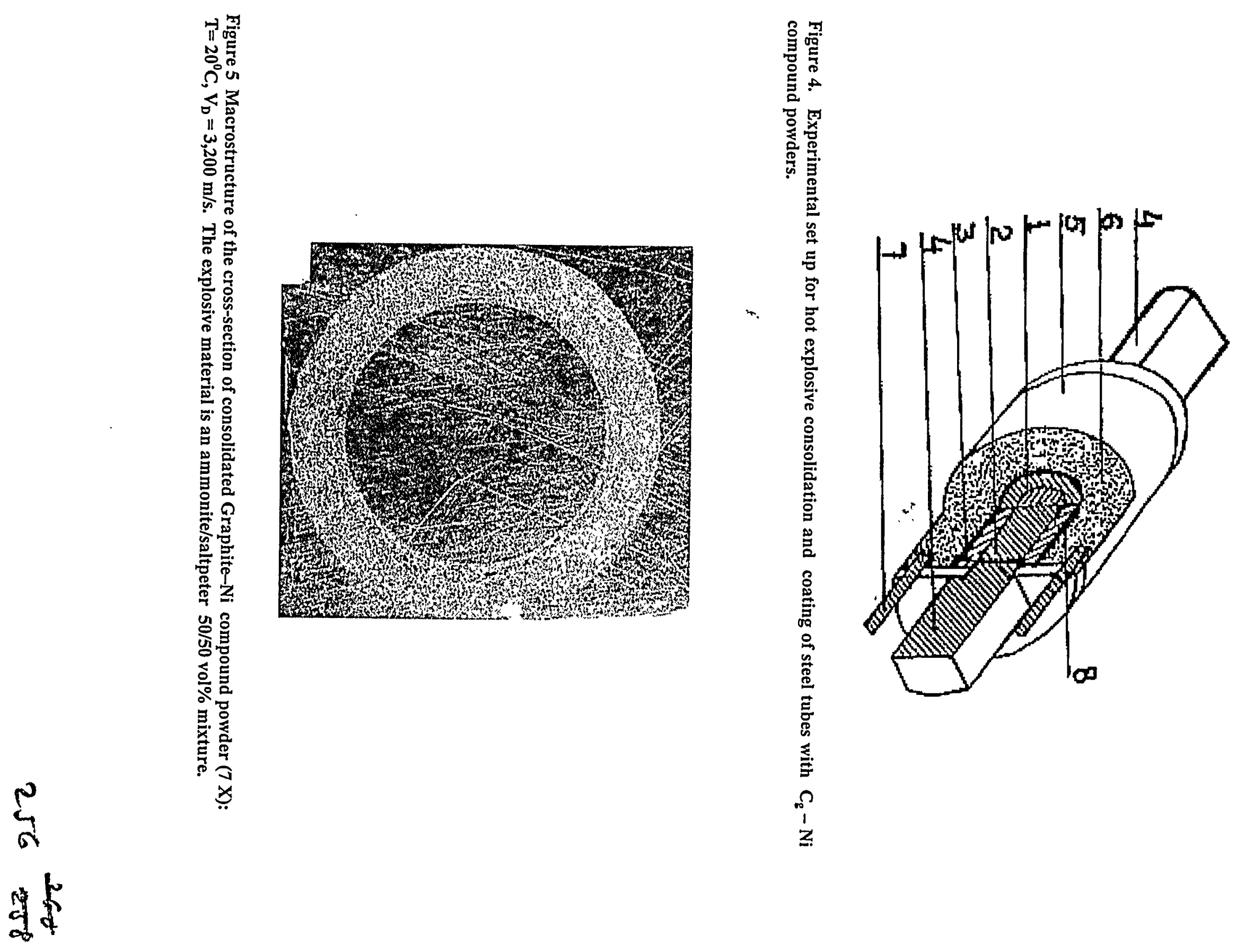


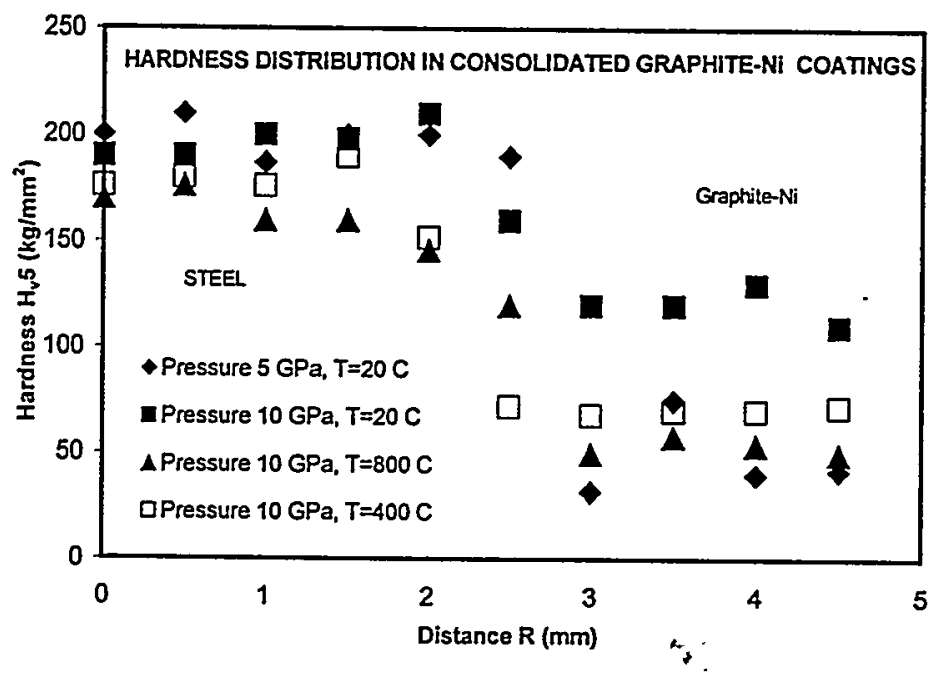

Figure 6. Hardness distribution of rigid Graphite - Ni coatings as a function of the radial distance.
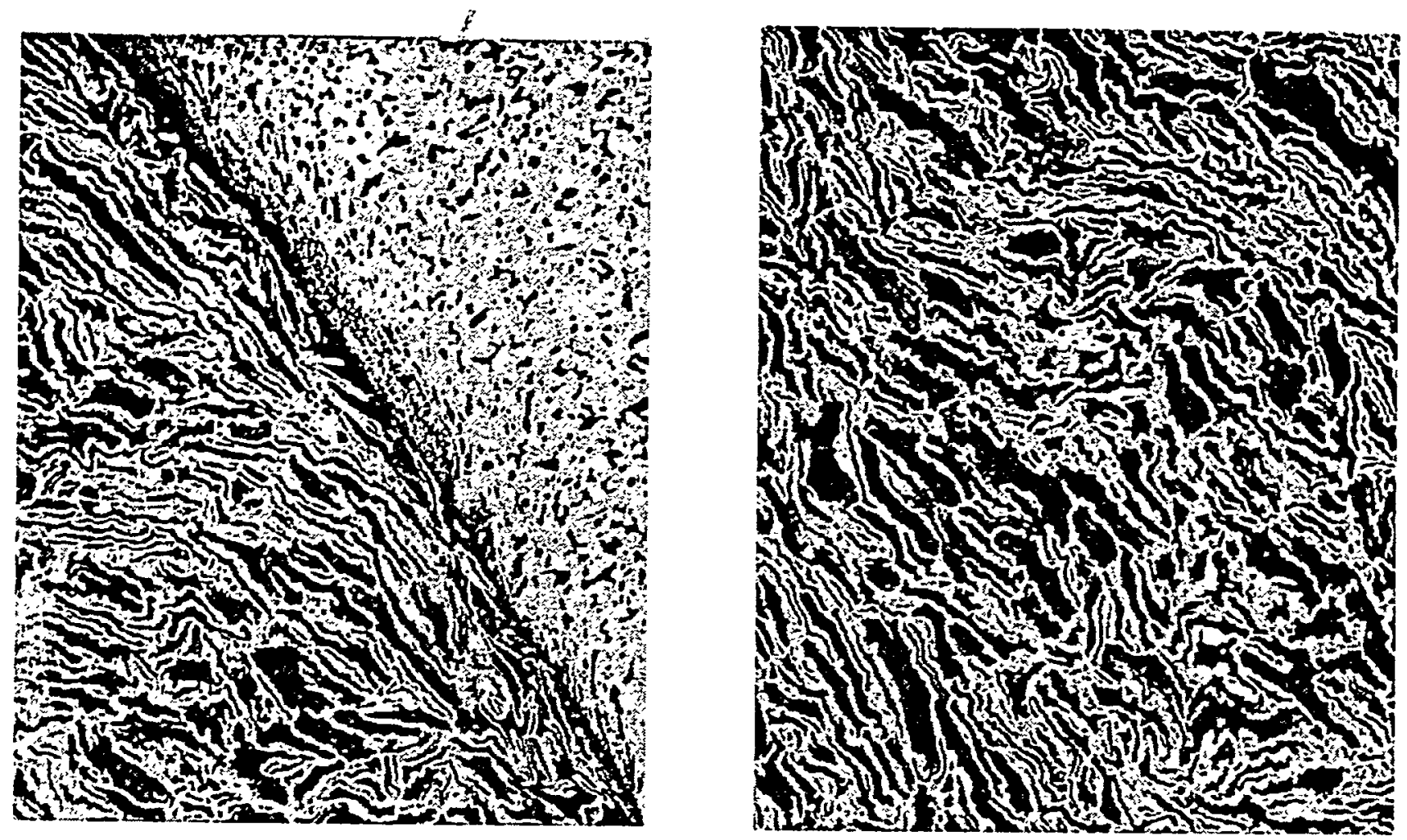

Figure 7. The microstructure of intermediate layer (a) and the coating (b) obtained by explosive compaction in hot conditions (200X): $T=1073 \mathrm{~K}$, Intensity of loading up to $5 \mathrm{GPa}$. 
The application of elevated and high temperature makes possible to obtain high density coatings with formation of an intermediate layer between the steel substrate and Graphite - Ni coating. The formation of intermediate zone can be observed from hardness distribution (Fig. 3) as well as from the microstructures which are presented in Figure 7. The microstructures the obtained compact/coatings are characterized by high density, and by uniform and stable structures. The intermediate layer can be observed in Figure. $4 \mathrm{a}$ between steel tube's wall and coating. The dimensions of the intermediate zone depend directly on the value of preheating temperature. The formation of the intermediate layer provides a strong bonding of the coating to the substrate material and gradual change in the value of the hardness and other properties, from the steel base to the $\mathrm{C}_{\mathrm{g}}-\mathrm{Ni}$ coating.

\section{CONCLUSIONS}

The application of clad Graphite-Ni powders and hot explosive consolidation technology enables us to compact Graphite -Ni composite powders with near theoretical density and to obtain rigid coatings from them with a graphite content of up to $50 \%(\mathrm{vol}$.).

The formation of Graphite-Ni composition coatings on steel surfaces can be accomplished with the formation of an intermediate layer between the steel and the coating.

The temperature generated during the explosive compaction has a beneficial effect on the process of compacting/coating of Graphite-Ni powders and on the formation of an intermediate layer between the coating and the supporting material.

\section{REFERENCES}

1. J.S. Rinehart, J. Pearson, Explosive Working of Metals, New York (1963).

2. R. Prummer, Explosivverdichung Pulvriger substanzen. Grundlagen, Verfahen, Ergebnisse, New York (1987).

3. M.A. Meйepc, L. E. Mypp, Shock-Waves and High-Strain-Rate Phenomena in Metals. New York and London (1981) 487-530.

4. L.A. Japaridze, Some Problems of Assessment of Stressed-Deformed State of Specimen, Compacted by Shock Loading, Tbilisi, Georgia (1991).

5. A.E. Carden and M. S. Kim "On the Mechanics of Dynamic Deformation of Metal Disks" in Metallurgical Applications of Shock-Wave-High-Strain-Rate Phenomena, Ed.. L.E.Murr, K.P. Staudhammer, M.A. Meyers, New York and Basel (1986)567-583.

6. . P.S. Follansbee, "High-Strain-Rate Deformation of FCC Metals and Alloys" in Metallurgical Applications of Shock-Wave and High-Strain-Rate Phenomena, Ed. L.E. Murr, K.P. Staudhammer, M.A. Meyers, New York and Basel (1986) 451-479.

7. E.R. Strutt, E.A. Olevsky, and M.A. Mayers; "Combustion Synthesis and Densification of Ceramics and Cermets", in Powder Materials: Current Research and Industrial Practices. Ed. F.D.S. Marquis, TMS, Warrendale, PA (1999) 73-89.

8. I. Sneddon, Fourier Transforms; New YorkToronto-London (1951).

9. A.A. Deribas, Fisics of Explosive Welding and Strengthening.

10. Tablitsi Fizicheskikh Velichin edited by I.K. Kikoin, Moscow, Atomizdat, 1005 (Russian).

11. L.V. Tikhonov et al. : «Mechanical Properties of Metals and Alloys» Kiev, Naukova Dumka (1986)567. 